\title{
Peertechz
}

\section{Solving the problem of post- operative airway obstruction in Nasal/Sinus Surgery}

\author{
Robert Kotler ${ }^{1 \star}$, Keith Wahl ${ }^{2}$ and Kimberly $\mathrm{J} \mathrm{Lee}^{3}$ \\ ${ }^{1}$ Clinical Instructor, Department of Surgery, Division of Head and Neck Surgery, David Geffen School of \\ Medicine at UCLA, Los Angeles, CA, USA \\ ${ }^{2}$ Clinical Assistant Professor, Retired, UCSD School of Medicine, Division of Otolaryngology, \\ Department of Surgery, La Jolla, CA, USA \\ ${ }^{3}$ Clinical Assistant Professor, Department of Surgery, Division of Head and Neck Surgery, David Geffen \\ School of Medicine at UCLA, Los Angeles, CA, USA
}

Received: 20 August, 2020

Accepted: 14 September, 2020

Published: 15 September, 2020

*Corresponding author: Robert Kotler, Clinical Instructor, Department of Surgery, Division of Head and Neck Surgery, David Geffen School of Medicine at UCLA, Los Angeles, CA, USA,

E-mail: rkotler@robertkotlermd.com

https://www.peertechz.com

Check for updates

\section{Introduction}

Sinus surgery, septoplasty-with or without turbinate reduction-and rhinoplasty are among the most common surgical procedures performed by our specialty. In 2006, 600,000 sinus surgeries were performed in the United States [1]. A recent paper reported more than 300,000 rhinoplasties done per year $[1,2]$. Septoplasties and ancillary procedures accounted for an additional 489,000 procedures [1].

\section{Packing or no packing, the Post-operative period is not popular with patients}

Some surgeons choose not to place any packing. However, patients still complain of impaired breathing due to endonasal edema, blood and mucus accumulation. Nasal and Sinus procedures may feature some surgeoninserted "packing," placed or injected into the nasal fossae, at the conclusion of the operation. In a National Interdisciplinary Rhinoplasty Survey, $39 \%$ of surgeons reported using packing $81 \%-100 \%$ of the time, with $81 \%$ of the surgeons leaving the packing in place for 0-3 days post-operatively [2].

\section{The common reasons/indications for packing are to:}

- Stabilize manipulated/repositioned/reconstructed elements in the proper and anatomically correct positions

- Prevent synechiae formation

- Reduce the chance of bleeding and prevent hematoma formation
- Act as a substrate for medications (e.g., antibiotics and steroids)

- Act as a conduit for topical medications to be instilled after surgery (e.g., nasal decongestant drops to reduce bleeding and/or relieve congestion)

Patients fear the post-op experience more than the surgery

Today it is common knowledge among prospective patients that nasal and sinus surgery may require packing or that even if not, the post-operative experience is not ideal. Such historical "bad press" is not quickly erased. Even contemporary surgical patients, whose surgery did not include packing, still report post-op nasal blockage, which often requires intervention, as the single most burdensome feature of the surgery. Pain, easily controlled with analgesics, ranks lower on the list of negative memories.

Surgeons who favor packing have a variety of excellent packing products. Mesh, clothlike absorbables, gelliquids, or the non-absorbable, non-adherent, and easily removable Telfa varieties. In addition, there are new packing substances on the horizon, as bioscience is learning to impregnate the materials with biologicals that stimulate healing.

For those patients for whom packing is indicated, they report that the standard one-to-five-day period of indwelling packing is the most unpleasant feature of the entire experience $[3,4]$. Tolerance levels among patients vary greatly, but whether " packed" or " unpacked", a blocked nasal airway can 
generates some anxiety and even claustrophobia. "It was as if someone left a clothespin on my nose and walked away," reported one unhappy patient.

A guaranteed post-op nasal airflow is the Win-Win for patient safety and comfort

Surgeons, tinkerers by nature, tend to fixate on surgical technique, embrace novel technology, innovative instrumentation in the pursuit of patient safety, and improved surgical results and operating room efficiency and economy. But, perhaps tunnel vision has been developed as surgeons labor in the nasal tunnels. Are surgeons losing opportunities to provide more patients with successful operations because they have neglected to also focus on patient comfort and satisfaction? Perhaps, particularly because few have stood in the patient's shoes; "Every so often, a doctor needs to be a patient. He will then be a better doctor."

\section{Are there prospective patients waiting on the sidelines?}

Appreciating the face-off between post-operative safety and healing objectives - and comfort - we have examined the products and devices, past and present, that purport to facilitate nasal breathing after nasal/sinus surgery, whether the nose is packed or not.

Some products, designed for dual packing-airway function, insinuate a pliable airway within a single piece of solid, foamlike packing material that expands when moistened (Figure 1).

The veteran and popular "Doyle Septal Splint," rather than a one-piece packing/airway device, is a different variety of airway hybrid: it features pre-shaped and pre-sized soft silicone sheaths that act as septal splints (Figure 2).

Fabricated onto each of the pair of splints are one-half diameter, or "hemi-tubes," designed to allow airflow. The Doyle septal splints are parabolic-shaped, and the attached hemi-tubes are curved to mirror normal airflow through the nose. The splint is seven $\mathrm{cm}$ long; the air tube is six $\mathrm{cm}$; the hemi-tube has a radius of $4 \mathrm{~mm}$. Sold as a right-and-left pair, both members are inserted astride the septum and sutured to each other using a mattress suture across the septum. The aim is to stabilize the post-resection septal cartilage, return the previously elevated septal perichondrium against the cartilage, and promote readherence of mucosa to cartilage. To accomplish

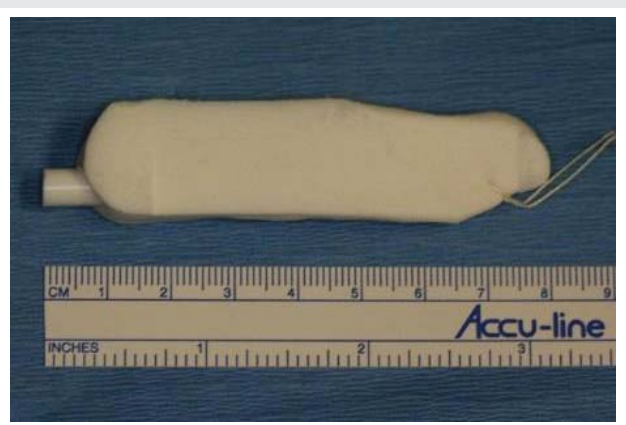

Figure 1: Combination airway and pack

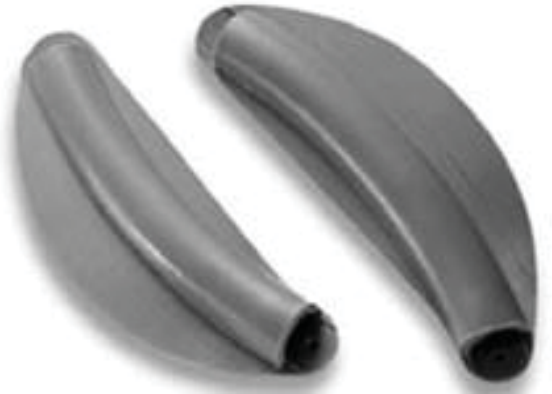

Figure 2: Doyle septal splints.

all this, the device must be secured to the cartilaginous septum through the mucosa, deep within the nasal passages, beyond the nostril opening, beyond the internal nasal valve, and even beyond the membranous septum. Thus, positioning of the splints relegates the anterior openings of the airway members to a position far inside the nasal fossae.

While this combination of a removable septal splint and an attached intranasal airway is conceptually attractive, the functional reality is that the nasal airway in-situ always becomes blocked and thus inoperative. Early in the postoperative period, the narrow hemi-tubes promptly and irrevocably clog with blood and mucus. The deep-interior location effectively prohibits the patient or caretaker from gaining access to these anterior openings to keep the tubes from blocking. The air passage is now defunct.

A burden imposed upon the surgeon and staff is that the sutured-in-place Doyle requires an office removal that is not a patient-favorite since the suture removal and delivery generates some discomfort as complete anesthesia is not attainable. Further, there is the additional time/labor cost to the practice. Many MDs delegate to their medical assistant or RN, but, their time is valuable also. As economic realities continue their pressure on MDs, efficiency and economy of surgical care always has a consequence for the " bottomline".

The commonality to all deep-seated packing/airway hybrid devices - not just the Doyle - are locationbased, post-operative inaccessibility. Other dual-purpose, removable packing devices, as mentioned earlier, are the Pure Pak ${ }^{\circledR}$, SlikPak $^{\circledR}$, and Venti-Pak ${ }^{\circledR}$. These products, into whose PVA foam bodies are seated a tube to ostensibly carry air, have been somewhat disappointing. Because immediately after surgery the nasal fossae quickly fill with secretions, the relatively narrow airflow tube can become blocked. Plus, their openings are not easily accessible for post-op, home-care maintenance.

We need to recognize that patients (who may be sedated by medications), and/or caregivers, are understandably reluctant to explore the nasal interior in the hope of re-opening blocked tubes and reestablishing functionality. Patients and their caregivers are justifiably intimidated and fearful of causing pain or "ruining" the operation. Realistically, laypeople should not be charged with performing intranasal procedures to reopen an inoperative medical device. 
An independent, single-purpose airway device is the best answer for satisfactory post-operative airflow and patient comfort

We have studied, evaluated, and analyzed the deficiencies and functional compromises of the dual-mission hybrids: the splint and airway and the packing and airway versions. Perhaps it is better not to merge two disparate missions into a single device. For better performance and patient comfort and satisfaction, perhaps it is wiser to separate the splinting/ packing and airway roles.

Since there is now an ever-increasing variety of packing devices, it seems advantageous to allow the surgeon to choose from among them. For any of these modern packing products, a dedicated, independent, and reliable device to provide the post-operative airway is an ideal teammate.

As a product of the above-mentioned studies, we have developed and fabricated a post-operative nasal airway device: a one-piece, dual-nasal airway appliance that is inserted by the surgeon at the end of the operation, before or after packing and/or optional septal splint placement (Figure 2). This device will provide a corridor for adequate air passage through both nasal passages without compromising splint's or packing's important functions. It is compatible with any current packing product.

The single piece, dual-nasal airway tube is made of soft (25+/-5 durometer), latex-free, medical-grade silicone. Length $=12 \mathrm{~cm}$, with centimeter graduations. Internal diameter $=5 \mathrm{~mm}$; outside diameter $=7.5 \mathrm{~mm}$. The right and left airway tubes are connected by an even softer, highly pliable bridge. This bridge connection to the anterior segments of the tubes prevents posterior slippage into the nasopharynx and assures visible anterior tube openings for easy and safe post-operative home care Figures 3,4.

\section{A study of airflow through the new device versus through existing hybrid airways}

The clinical value of any airway appliance rests on the volume of air that passes through the air tube en route to the lungs. Pouiseuille's Law*, which quantitates laminar airflow

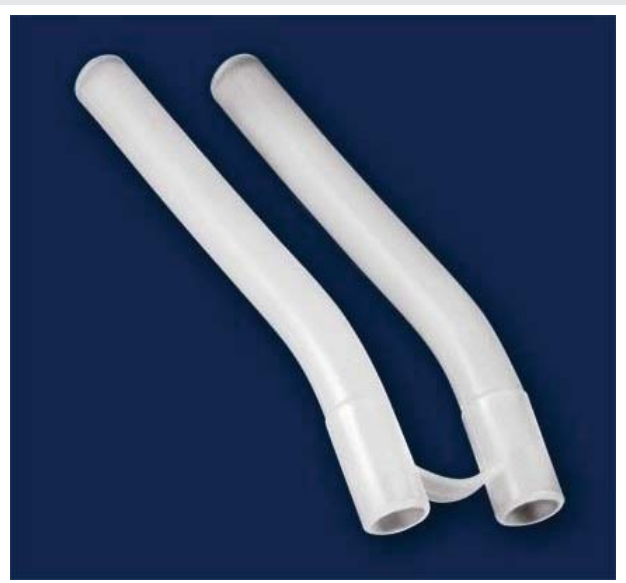

Figure 3: New nasal airway-only device.

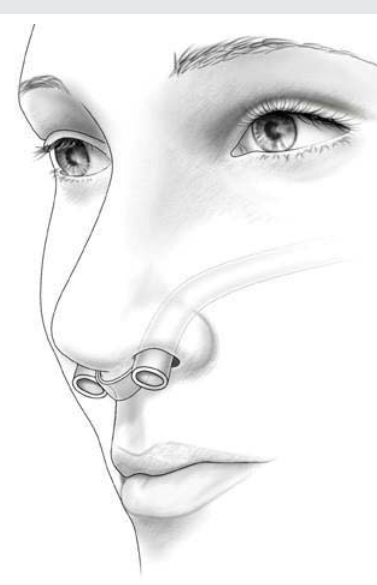

Figure 4: Illustration of airway device in nasal pass ages.

through a definable and measurable passage governs the analysis of nasal airway devices [5-7].

Poiseuille determined that the wider the tube radius, the lower the airflow resistance. More importantly, the change in radius is not proportional to the change in resistance but yields a four-fold increase in resistance for a given reduction in radius. Therefore, a small change in radius significantly affects either flow rate or pressure drop required to achieve the same flow $[8,9]$. If the lumen of the airway becomes obstructed or narrowed, the effective radius of air flow will be significantly reduced, negatively affecting air flow to the patient.

Accepting that small increases in an air tube's diameter increases airflow exponentially, it is possible to scientifically assess, applying Poiseuille's Law, what might be a major difference in airflow through the single-mission new device contrasted with a popular airway-splint hybrid, the Doyle Septal Splint, and an airway-pack hybrid, the Venti-Pak ${ }^{\circledR}$.

The flow through each member of the Post-operative Nasal Airway is $188.1 \mathrm{~cm}^{3} / \mathrm{pa}-\mathrm{s}$ (or $376.2 \mathrm{~cm}^{3} / \mathrm{pa}-\mathrm{s}$ through both tubes) based on a length of $7.5 \mathrm{~cm}$ and a radius (internal diameter) of $0.5 \mathrm{~cm}$. Airflow through the Doyle Septal Splint is $14.7 \mathrm{~cm}^{3} / \mathrm{pa}-\mathrm{s}$ (or $29.6 \mathrm{~cm}^{3} / \mathrm{pa}-\mathrm{s}$ through both nostrils), based on a length of $6.2 \mathrm{~cm}$ and radius of $0.5 \mathrm{~cm}$. Reflecting the airways' differential diameters and length, the airflow through the new independent airway device is $\mathbf{1 2 . 8}$ times greater than that through the Doyle Septal Splint.

*Poiseuille's law states that the flow rate Q is dependent on fluid viscosity $\eta$, tube length $l$ and the pressure difference between the ends.

Pouiseuille's Law: $V=R P \pi r^{4} / 8 \eta l$, where $V=$ air flow, $R P=$ the difference in pressure between the two points, $r=$ radius of the tube, $\eta=$ gas velocity, and $\mathrm{l}=$ length of the tube. Using Poiseuille's Law, assuming negligible change in pressure, the laminar air flow through the Doyle Septal Splint is $14.7 \mathrm{~cm} 3 /$ pa-s (or $29.6 \mathrm{~cm} 3$ / pa-s through both nostrils), based on a length of $6.2 \mathrm{~cm}$ and radius of $0.5 \mathrm{~cm}$. Note that each Doyle airway is a hemi-tube, so the airflow through each of these hemi-tubes, calculated by Poiseuille's Law, was halved. The flow through each side of the post-operative 
nasal airway is $188.1 \mathrm{~cm} 3 /$ pa-s (or $376.2 \mathrm{~cm} 3 /$ pa-s through both tubes) based on a length of $7.5 \mathrm{~cm}$ and radius of $0.5 \mathrm{~cm}$.

The photo below visually compares the lumena of the Doyle Septal Splint and the new nasal airway device Figure 5.

The Venti-Pak ${ }^{\circledR}$, a prototypical airway-packing hybrid, has an air tube inside diameter of $4 \mathrm{~mm}$. Using Poiseuille's Law, the calculated airflow through a Venti-Pak ${ }^{\circledR}$ is $82.5 \mathrm{~cm}^{3} / \mathrm{pa}-\mathrm{s}$. While delivering greater air flow than thru the Doyle Septal Splint, the Venti-Pak ${ }^{\circledR}$, also delivers more than $50 \%$ less air to the nasopharynx than the newer device Figure 6.

The tube is introduced at the conclusion of the operation prior to insertion of any packing, whether solid or gel. After initial, partial insertion, using a standard, thin-tip nasal speculum, inspect the nasal interior to ascertain the position of the airways within the nasal cavity Figure 7.

Under direct vision, advance the airways further into the nose. Next, using the inferior speculum blade or a bayonet forceps, direct each airway downward onto the floor. The tube will snap into place onto the floor of the nose and maintain that position, lateral to the pre-maxillary bone and medial to the inferior turbinate Figures 8-10.

After insertion and seating of the nasal airway, the surgeon passes the 10Fr plastic suction catheter through each tube and suctions fluids from the pharynx. This maneuver also confirms that the back opening of the device is unobstructed. Later, the anesthesia specialist, using the same flexible suction catheter, will avail himself of this direct pathway to the pharynx for suctioning blood and mucous from throat.

At the end of the procedure, prior to awakening the patient, the same 10Fr. plastic suction catheter is passed by the anesthesiologist through each nasal airway tube to suction

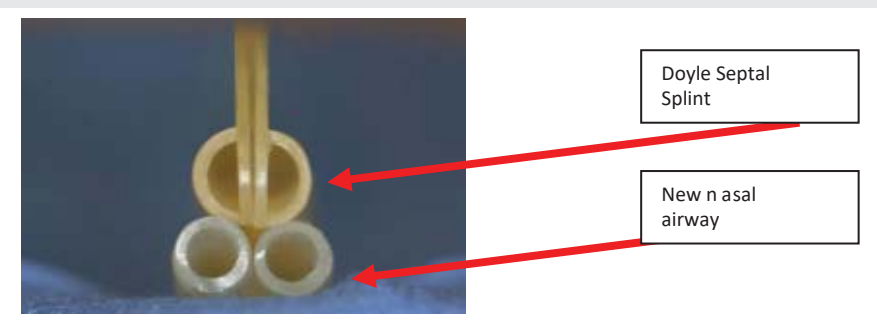

Figure 5: Comparative view of cross-sectional diameter of doy le splint with the post-operative nasal airway.

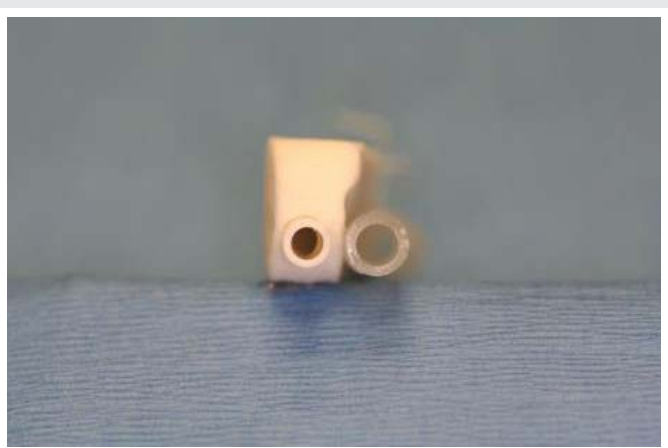

Figure 6: Comparative view of cross-sectional diameter of Venti-Pak (left) with the post-operative nasal airway (right).
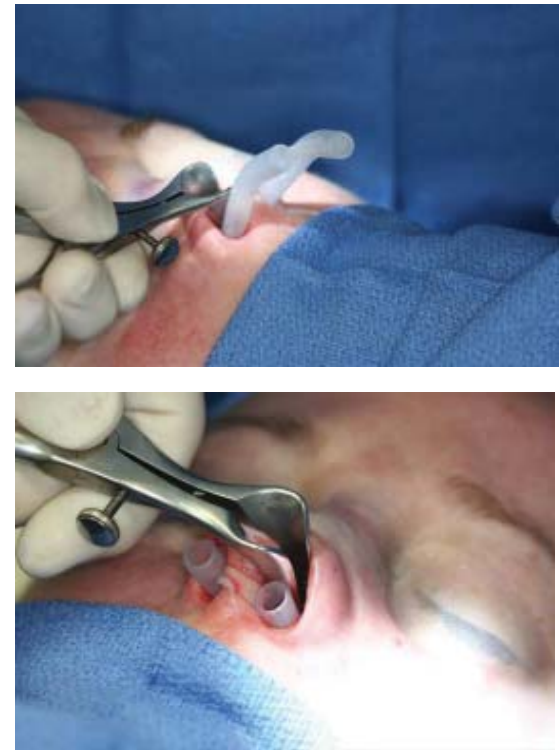

Figure 7: The Clinical Application of the Post-operative Nasal Airway.

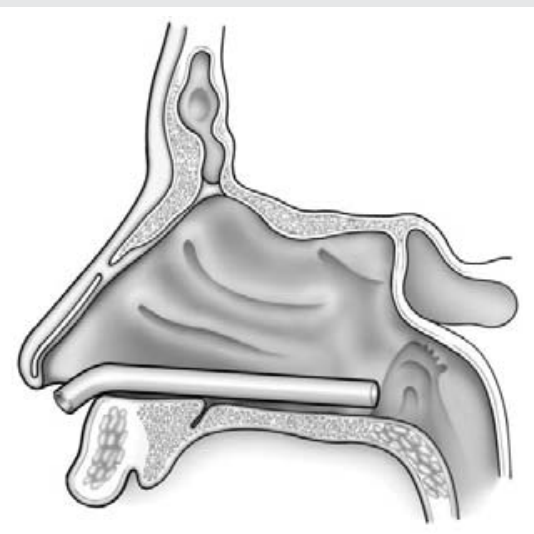

Figure 8: View of airway in place. No nasal packing.

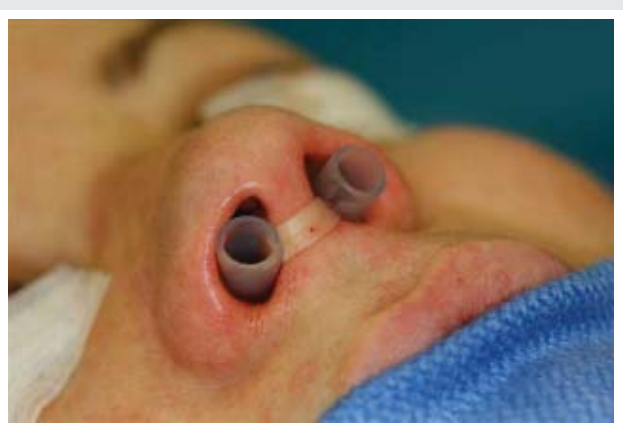

Figure 9: When both nasal tubes are properly seated, the bridge connecting the two will be flush against the columella.

NOTE: If an open rhinoplasty procedure has been performed, the surgeon may wish to divide the bridge and secure each tube separately, rather than have the bridge contact the transcolumellar incision.

the oropharynx. Our anesthesiologists expressed preference for such access into the pharynx for suctioning while the patient is still asleep, rather than having to struggle to perform oralpharyngeal toilet, as the patient is emerging from anesthesia.

For home care, the patient is provided a 3cc Luer-Lok syringe and adapter tip. An illustrated instruction sheet, 
provided with the airway kit, explains the simple technique of irrigation with tap water, as needed, to maintain clear airways Figure 11.

\section{The clinical experience: 150 patient case histories}

In the senior author's private practice, 150 patients scheduled to undergo reconstructive nasal surgery- nasal septoplasty and bilateral inferior turbinate resection, with or without rhinoplasty-were offered and consented to placement of the nasal airway.

In all septoplasty/turbinate cases, the senior author always inserted two different packings: one absorbable and one nonabsorbable (Figure 12). The absorbable was a two-ply sheet of either gauzelike Surgicel ${ }^{\circledR}$ or absorbable hemostatic gauze ActCel $^{\circledR}$ draped over the turbinate remnant. The removable pack was a folded (thus two-ply) single sheet of non-adherent Telfa ${ }^{\circledR}$ coated on both sides with tetracycline ointment (Figure 13). As a means to ease insertion of the absorbable packing (which becomes a bit unmanageable when moistened by mucus or blood), the ointment-coated, now surface-sticky Telfa ${ }^{\circledR}$ pad was used to "carry and deliver" the gauze to its home over the medial edge of the turbinate (Figures 14-16). Then, the Telfa ${ }^{\circledR}$ pad was placed against the septum to fulfill its overall packing mission. A remnant suture from the surgical procedure is secured to the right and left Telfa ${ }^{\circledR}$ pads before insertion. This was tied to its opposite member over the columella or taped to the adjacent cheek, to anchor and prevent accidental posterior displacement of the Telfa ${ }^{\circledR}$ pad. The suture-string also facilitates the pack's removal.

Ointment to facilitate placement non-adherent, nonabsorbable pad trimmed to size. Of absorbable packing.
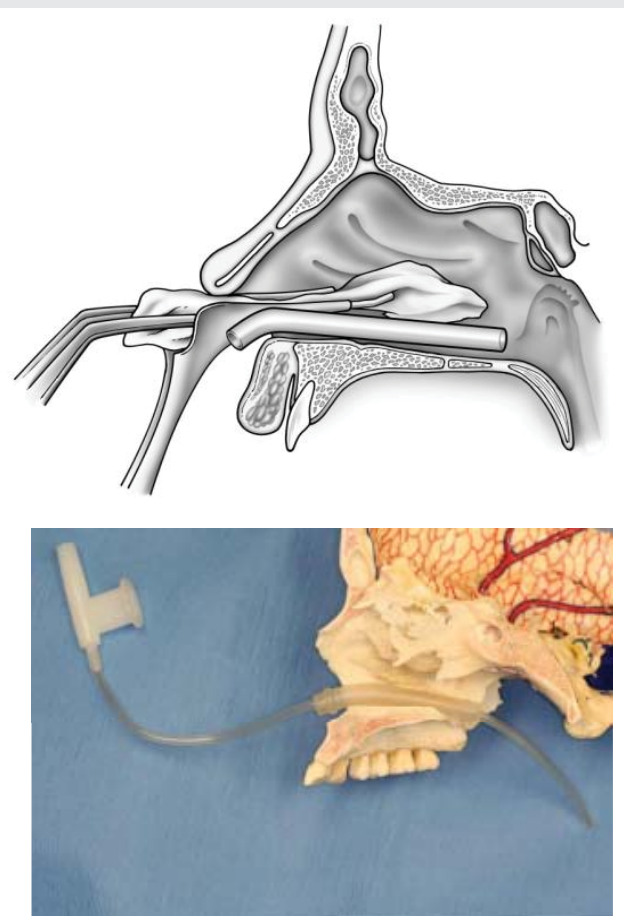

Figure 10: If the surgeon chooses to pack, the packing material of choice is placed as speculum stabilizes the nasal airway.

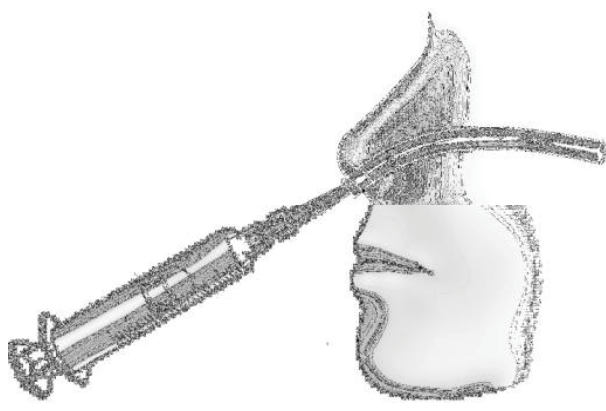

Figure 11: Home Care.

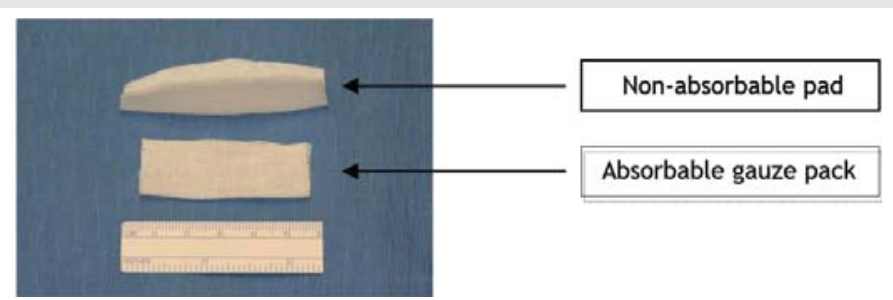

Figure 12: Absorbable gauze packing and removable, non-adherent, non-absorbable pad.

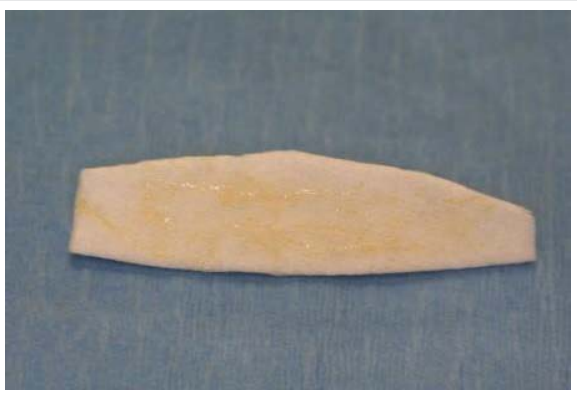

Figure 13: Non-adherent pad coated with tetracycline ointment to facilitate placement of absorbable packing.

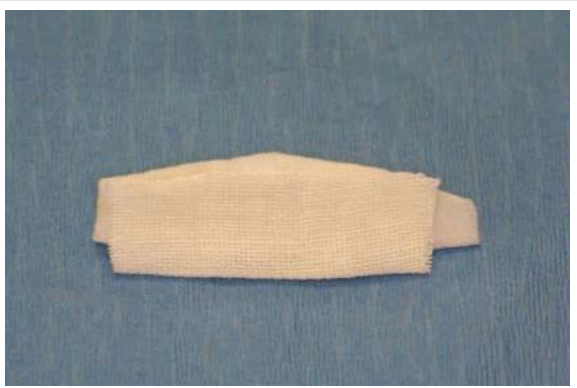

Figure 14: Absorbable gauze packing and removable non-adherent, non-absorbable pad trimmed to size.

Positioned right inferior turbinate and non-adherent nasal pack for each ease of right nasal cavity. Airway tube lateral nasal wall. Insertion to cover turbinate.

To prepare the patient for ease of tube and non-absorbable pack removal, five drops of an anestheticdecongestant solution (equal volumes of oxymetrazolamine and tetracaine $2 \%$ ), were instilled into the nasal cavities to anesthetize and decongest the mucosa in anticipation of tube and pack removal. The tubes easily slid out of the nasal fossa, and the non-absorbable pads were likewise easily extracted. The absorbable packing was 


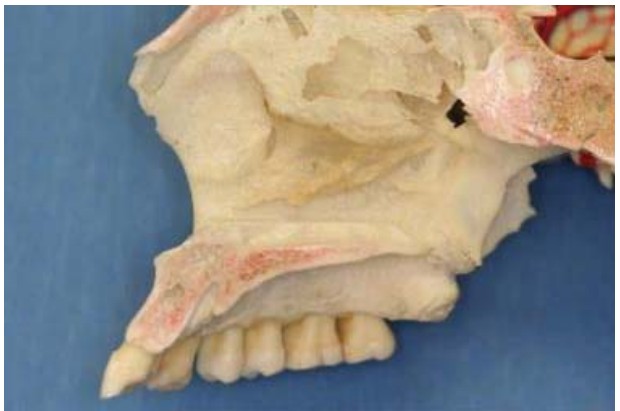

Figure 15: View of nasal interior demonstrating positioned right inferior turbinate right nasal cavity. Airway tube lateral nasal wall.

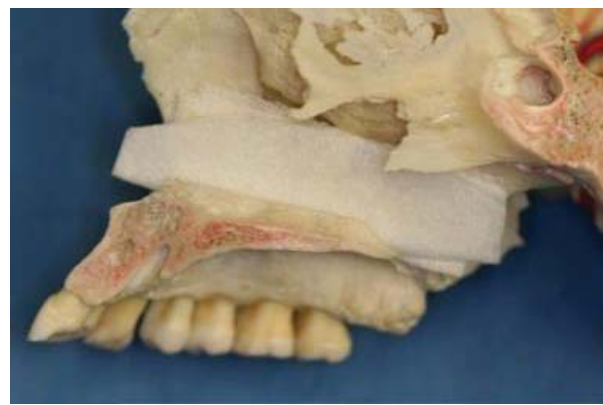

Figure 16: Absorbable gauze adherent to non-adherent nasal pack for each ease of insertion to cover turbinate.

absent, and mucosal surfaces demonstrated early healing. There were no remnant signs of any internal damage from the indwelling tubes in any of the cases. Significantly, there was not a single episode of significant epistaxis at time of tube and pack removal that required intervention of any kind. One patient had a bleeding episode from a posterior turbinate resection site and from a posterior septoplasty site, 11 days after surgery that required placement of absorbable packing. The nasal airway had not been in contact with either bleeding location.

\section{Analysis of patient experience}

Of the 150 patients, 146 sustained the tube placement for one to six days after surgery. Typically, rhinoplasty-only patients require the airway for only 24 hours, the septoplasty/ turbinate patients with or without rhinoplasty patients are scheduled to have the airway and packing in place for five days. Three septoplasty/turbinate/rhinoplasty patients requested removal because they were not interested in, or capable of, the home irrigation of the tubes necessary to maintain patency and airflow. One septoplasty/turbinate/rhinoplasty patient took it upon himself to remove the airway after three days. No adverse consequences ensued from any premature removal.

Of those 146 patients whose airways remained in place the prescribed period of time, there was a subset of 33 patients who had previous surgeries with complete packing and no airway prior. One patient within this subgroup had three failed septorhinoplasty procedures. All 33 reported a positive experience with and preference for the nasal airway.

Of the remaining 113 study patients, there was a voluntary control group of 19. Those patients had identical packing placed bilaterally, but one nasal passage also had place an airway tube. All 19 reported preference for the "airway side" vs. the packedwithout-airway side.

Of the 94 patients with the routine, bilateral packing and bilateral airtubes in place, 91 reported a positive experience.

The overall patient satisfaction rate was $98 \%$.

\section{Conclusion}

Though nasal and sinus surgery is common and widespread, there is no consensus on choice of nasal packing. Further some surgeons prefer not to pack. Those who pack feel that nasal packing - in some form-is important to prevent postoperative complications such as synechiae, bleeding, and anatomic destabilization.

Despite their importance and value, contemporary packing materials and devices and airway appliances generate patient dissatisfaction. Even those patients who do not endure packing are not satisfied with the airway immediately after surgery because of lining mucosal edema,and blood and mucus stasis. Pack or no-pack, nasal obstruction generates anxiety, claustrophobia, and negative public relations. For these routine and generally successful procedures to be rejected by patients because of post-operative dissatisfaction - which need not occur - is unfortunate. There are perhaps tens of thousands of potential patients who would be approaching nasal surgeons requesting the operation had the procedure's bad public image not scared them off.

As a result of investigating the issue of patient comfort and safety in the nasal/sinus surgery post-operative period, the new medical device described in this report provides a safe airway that contributes to patient comfort and, ultimately, provides a more satisfactory post-surgical experience.

\section{Author contribution}

The authors acknowledge the input, advice, and suggestions - throughout the study and development of the new airway device - of the following colleagues and advisors: William Binder, MD; Joe Parell, MD; Ronald Strahan, MD; Robert Meyers, MD; Gary Becker, MD; Kenneth Geller, MD; Kevin Tehrani, MD; Sheldon Schneider, BS; Craig Sherman, JD; A. Norman Enright, BA, MBA; Lindsey Kotler, BA; Jerry Berliant; Doris Porter, RN, CNOR; DeLoris Everts, RN, CNOR; Toya Twitty, ORT; Tammi Jollata, CST.

Special thanks to Mary Jakubowitz, Talia Dadon and Aimy Cohen for their administrative assistance.

John Reid, Reid Medical, San Diego, CA, provided nasal endoscopic exam and recording equipment.

Airway device concept and prototype design by Burt Bochner, Culver City, CA and Art Shulenberger, San Leandro, CA. Airway device fabrication by Robert Hallock, Concept Modelz, Livermore, CA. 


\section{References}

1. Cullen KA, Hall MJ, Golosinskiy A (2009) Ambulatory Surgery in the United States, 2006. Natl Health Stat Report 11: 1-25. Link: https://bit.ly/3kj9HY3

2. Warner J, Gutowski K, Shama L, Marcus B (2009) National Interdisciplinary Rhinoplasty Survey. Aesthetic Surgery Journal 29: 295-301. Link: https://bit.ly/3hpuPtP

3. Chheda N, Katz A, Gynizio L, Singer A (2009) The Pain of Nasal Tampon Removal After Nasal Surgery: A Randomized Control Trial. Otolaryngol-Head Neck Surg 140: 215-217. Link: https://bit.ly/3iu5HmP

4. Weber R, Hochapfel F, Draf W (2000) Packing and Stents in Endonasal Surgery Rhinology 38: 49-62. Link: https://bit.ly/32qxizF
5. Ogretmenoglu O, Yilmaz T, Rahimi K, Aksöyek S (2002) The Effect on Arterial Blood Gases and Heart Rate of Bilateral Nasal Packing. Eur Arch Otorhinolaryngol 259: 63-66. Link: https://bit.ly/2ZwvldF

6. Lubianca-Neto JF, Sant'anna GD, Mauri M, Arrarte JL, Brinckmann CA (2000) Evaluation of Time of Nasal Packing After Nasal Surgery: A Randomized Trial. Otolaryngology-Head Neck Surg 122: 899-901. Link: https://bit.ly/32t1dHO

7. Arya AK, Butt O, Nigam A (2003) Double-blind Randomised Controlled Trial Comparing Merocel with Rapid Rhino Nasal Packs After Routine Nasal Surgery. Rhinology 41: 241-243. Link: https://bit.ly/3iwDXOo

8. Fairbanks DNF (1986) Complications of Nasal Packing. Otolaryngology-Head and Neck Surgery 94: 412-415. Link: https://bit.ly/2FvUBzl

9. Johns Hopkins School of Medicine's Interactive Respiratory Physiology. Link: https://bit.ly/3ioxt4a

\section{Discover a bigger Impact and Visibility of your article publication with}

\section{Peertechz Publications}

\section{Highlights}

* Signatory publisher of ORCID

* Signatory Publisher of DORA (San Francisco Declaration on Research Assessment)

- Articles archived in worlds' renowned service providers such as Portico, CNKI, AGRIS, TDNet, Base (Bielefeld University Library), CrossRef, Scilit, J-Gate etc.

* Journals indexed in ICMJE, SHERPA/ROMEO, Google Scholar etc.

* OAI-PMH (Open Archives Initiative Protocol for Metadata Harvesting)

* Dedicated Editorial Board for every journal

* Accurate and rapid peer-review process

* Increased citations of published articles through promotions

* Reduced timeline for article publication

Submit your articles and experience a new surge in publication services (https://www.peertechz.com/submission).

Peertechz journals wishes everlasting success in your every endeavours.

Copyright: @ 2020 Kotler R, et al. This is an open-access article distributed under the terms of the Creative Commons Attribution License, which permits unrestricted use distribution, and reproduction in any medium, provided the original author and source are credited. 